Allen-Collinson, $\mathbf{J}$ (2018) 'Weather work': embodiment and weather learning in a national outdoor exercise programme, Qualitative Research in Sport, Exercise and Health, 10 (1): 63-74. http://www.tandfonline.com/eprint/JpJbilzsXMPTwaNUHUJb/full

\title{
'Weather work': embodiment and weather learning in a national outdoor exercise programme
}

\section{Jacquelyn Allen-Collinson}

School of Sport \& Exercise Science, University of Lincoln, Lincoln, LN6 7TS, UK

Professor Jacquelyn Allen-Collinson, jallencollinson@lincoln.ac.uk, +44 0152283

7728; ORCID: 0000-0003-2146-8000; LinkedIn:

https://www.linkedin.com/in/jacquelyn-allen-collinson-56297b48/;

Twitter: https://twitter.com/HARTResearch

Email: jallencollinson@lincoln.ac.uk

Jacquelyn Allen-Collinson is Professor in Sociology and Physical Culture, and Director of the Health Advancement Research Team (HART), University of Lincoln, UK. Currently pursuing her interest in combining sociology and phenomenology, her research interests include the lived experience of health and illness conditions in sport and physical cultures, together with the sociology of the senses, identity and identity work. 


\section{'Weather work': embodiment and weather learning in a national outdoor exercise programme}

Over the past 25 years, UK government policy exhortations to promote and increase exercise and physical activity levels in the population have increased in volume. In recent years, too, there has been growing sociological interest in exercise and physical activity embodiment issues, including within phenomenologically-inspired research into lived-body experiences. This article contributes original insights to a developing body of phenomenological-sociological empirical work in this domain, in addressing the lived experience of organised exercise in outdoor environments, and specifically in theorising the role of 'lived weather' in contouring these experiences. It thus addresses the call by Vannini et al. (2012) to remedy the notable 'absent-presence' of weather in much social science research. Drawing upon data from a two-year multi-disciplinary, multi-institutional ethnographic study of a nationwide exercise programme in Wales, UK, this article examines participants' ( $n$ = 146) lived experience of weather, and theorises their 'weather learning', and 'weather work', both of which emerged as highly salient in the findings.

Keywords: weather; weather work; phenomenology; phenomenological sociology; outdoor exercise; physical activity

\section{Introduction: exercise in the outdoors}

In the United Kingdom (UK), government exhortations to increase the physical activity levels of the population have increased in volume over the past 25 years or so, and the Department of Health has issued a series of physical activity guidelines and fact sheets for the populace generally and also for specific groups, including children and young people (5-18 years) and older adults (65+ years) (see Department of Health 2011). The UK guidelines draw on pronouncements from the World Health Organisation (WHO 
2010), which published its global recommendations on physical activity for health in 2010. There is widespread recognition of the positive contribution to health made by physical activity and exercise (Department of Health 2011), and conversely of the link between physical inactivity and higher levels of chronic diseases and premature mortality (Hardman and Stensel 2003). The UK government has therefore sought to promote 'healthy exercise', as a means of increasing physical activity levels and improving population health, including via Exercise Referral Schemes (ERS), and Physical Activity Referral Schemes (PARS). These schemes have been used since the early years of the 1990s to 'prescribe' exercise and/or physical activity for those with extant physical and/or mental health problems (Crone et al. 2008, Henderson et al. 2017), and also to help prevent health problems developing (Gidlow et al. 2005). Referral is made by a health practitioner, most usually a General Practitioner (GP).

Not all exercise or physical activity programmes require formal GP referral, however. A key example of a national physical activity programme requiring no formal healthcare practitioner referral was the Welsh Mentro Allan (Venture Out) Programme, funded by the UK National Lottery (the Big Lottery Fund ${ }^{i}$ or BLF), as part of the Community Sport Initiative, and rolled out across Wales from 2005-2011. Mentro Allan had the aim of increasing physical activity levels in a range of 'target groups', deemed to be at high risk of lack of physical activity. These groups included older people, women, Black and Minority Ethnic (BME) communities, people with physical disabilities, mental health service users, carers, people at risk of rural isolation, and people on low incomes. These groups are, of course, not homogenous categories; an issue that was raised with the Programme Steering Group on many occasions, and was reflected in the subsequent findings. One of the key aims of Mentro Allan was to use outdoor environments in Wales in order to stimulate healthy behaviour change and increase people's physical activity 
levels, and it is upon the outdoors and particularly the weather-related experiences of Mentro Allan participants that I focus in this article. Surprisingly, as Vannini and colleagues (2012) signal, there is currently a considerable social-science lacuna in terms of qualitative research on the weather and people's weather experiences, even though the ways in which people experience and talk about weather are highly significant in social life.

In relation specifically to outdoor exercise, in England and Wales this has been in structural decline since at least the 1970s (Curry and Brown 2010). In 2007, Natural England reported that the total number of outdoor visits had fallen by $45 \%$ since the 1970s, and its Chief Executive noted (Natural England 2007, p.1) that people were 'missing out on the wide range of benefits that (recreation in) the natural environment offers, particularly to their health and wellbeing'. The Mentro Allan Programme sought to draw on the benefits of the 'natural' environment' and 'green space' for physical health (Maas et al. 2006, Barton et al. 2009) and also for mental health (Bowler et al. 2010). The importance of the latter should be highlighted, given that the World Health Organization (WHO 2003) estimates that depression and related mental illnesses will, by 2020, become the largest manifestation of ill health globally. The social-structural dimensions of low levels of outdoor exercise (not necessarily outdoor physical activity) are of salience also, for some of the primary health problems linked to a lack of exercise have a strong socio-economic dimension, occurring predominantly amongst lower income groups, and the less educated (WHO 2003).

In England, schemes analogous to Mentro Allan in not requiring formal referral by a healthcare professional, include The Walking the Way to Health Initiative (WHI), introduced in the 1990s to promote exercise amongst more 'sedentary' people (Natural England 2007). Not only has the countryside been favoured in exhortations to take 
outdoor exercise, but in urban, metropolitan areas 'health walk' schemes have been devised (e.g. Curry 2009). As part of the UK Government's Change4Life healthy living campaign, the Walk4Life campaign, encourages people to download differentiallygraded walks with free maps for their local area. The Department of Health introduced a National Step-O-Meter Programme (NSP), as a result of the UK Government's 'Choosing Health' White Paper, published in 2005. The NSP Programme seeks to make pedometer use accessible and affordable for 'at risk' or 'hard to reach' groups, deemed to be too sedentary (Jarrett et al. 2004).

This is some of the policy and practice context in which the national Mentro Allan Programme was developed. The Programme is described in more depth below, along with the methodological approach taken to investigate the experiences of Programme participants. Before that, a brief overview of the theoretical framework of phenomenological sociology is provided, as I consider the influence of the weather on participants' experiences of, and motivations to, undertake exercise in the outdoor projects offered by Mentro Allan. The role of 'weather work' emerged as salient, as discussed below.

First, I address some definitional issues. As has been noted (e.g., NHS Health Scotland, 2007) currently there is no consensus regarding the definition of physical inactivity or 'sedentarism', including within public health policy documentation. Although there has been a shift more recently to referring to an 'inactive' rather than a 'sedentary' lifestyle (Pate et al. 2008), there similarly exists no standard definition of this term either. With regard to the distinction between physical activity and exercise, the definition of physical activity utilised here is a basic and long-standing one (see Caspersen et al. 1985): any bodily movement produced by skeletal muscles that results in energy expenditure. The term exercise is used to cover actions with an intention to 
move, often with a structured and/or repetitive pattern and a goal of improving or sustaining health and/or fitness. The aim of exercise is often to achieve a beneficial level of fitness and health, both physically and mentally. This latter was a key aim of the Mentro Allan programme, described under 'The Research' section below. First, the theoretical framework of phenomenological sociology, used here to explore embodiment issues and experiences of 'being-in-the-weather' (Vannini et al. 2012), is portrayed.

\section{Theoretical perspectives on the 'weather-world'}

Over the last two decades, social science interest in embodiment issues has burgeoned in relation to the domains of sport, physical activity and exercise, including a developing field of phenomenologically-inspired analyses of the lived experience of exercise and physical cultures (see for example, Kerry and Armour 2000, Hockey and Allen-Collinson 2007, Allen-Collinson 2009, 2011a, 2011b, Hogeveen 2011, Martínková and Parry 2011, Ravn and Hansen 2013). To give a flavour of the coverage of this expanding domain, this corpus includes research on walking (Darker et al. 2007, Crust et al. 2011), climbing (Crust et al. 2016, Swann et al. 2016) running (Allen-Collinson and Hockey 2011, Ronkainen et al. 2014, Hockey and Allen-Collinson 2015), parkour and free-running (Clegg and Butryn 2012), gardening (Hale et al. 2011), and exercise/physical activity programmes (Crust et al. 2014, Allen-Collinson and Leledaki 2015) to give just some examples.

The application of phenomenologically-inspired perspectives has also generated social-scientific interest in the sensory, aesthetic aspects of embodiment in physical cultures (e.g., Hockey and Allen-Collinson 2007, Sparkes 2009, Allen-Collinson and Hockey 2011, Sparkes and Smith 2012, Allen-Collinson et al. 2016). This research contributes to a developing body of sensory studies within sport and physical cultures 
more widely. Sparkes (2009), for example, draws on sensorily-evocative autoethnographic vignettes of cricketing, footballing and gym experiences, whilst Wacquant (2004) and Spencer (2014) provide ethnographic studies of boxing and mixed martial arts respectively, which highlight some of the sensory aspects of participation. Other examples within this sensory corpus include Humberstone (2011) on windsurfing, Hockey and Allen-Collinson's (2007) study of the sensory dimension of sporting embodiment generally, together with research on distance running and scuba diving specifically (Allen-Collinson and Hockey 2011). In the aquatic environment too, Merchant (2011) provides a vivid videographic study of scuba-diving, and in her auto/ethnographic work, Throsby (2013) evocatively describes the (sometimes unexpected) sensory pleasures of endurance swimming. These are just some examples of the sensory turn in qualitative research in sport and exercise. In earlier work, I have included detailed descriptions of phenomenologically-inspired research approaches (see for example, Allen-Collinson 2009, 2011a) so here I provide just a brief summary for those unfamiliar with some key tenets of phenomenology.

Originally developed by the German philosopher, Edmund Husserl (1970), 'modern' phenomenology is a rich, complex and multi-stranded philosophical tradition. The term 'phenomenology' is taken from the Greek root phôs (light), from which the English phenomenon derives, meaning something perceived (placed in the light) in consciousness. Phenomenology is therefore the study of phenomena, things as they present themselves to, and are perceived in consciousness. The relationship between human consciousness and the world lies at the heart of much phenomenology. Phenomenological researchers adopt the 'phenomenological attitude', involving epoche or bracketing (see Allen-Collinson 2011a), in order, temporarily, to 'step aside' from the world of everyday, taken-for-granted understandings that we term the 'natural attitude'. 
Phenomenologists contemplate what it is to be a participant in the world, and how things present themselves to us (Sokolowski 2000).

Furthermore, existential phenomenologists such as Merleau-Ponty (2001) sharpen the focus upon the corporeal elements of existence, highlighting how the 'lived body' fundamentally links mind-body-world, in Dasein - literally 'there being', or our 'beingin-the-world'. This form of existential phenomenology has proved productive in researching a range of physical activities and cultures and leisure activities, such as football (Hughson and Inglis 2002), running (Hockey 2011, Allen-Collinson 2011b), fell-running (Nettleton 2013), and dance (Ravn and Hansen 2013). The current article draws upon what I have termed phenomenologically-inspired sociology; a form of phenomenology that acknowledges and addresses the effects of social-structural and cultural location upon our lived-body experiences, rather than seeking to identify universal, 'everywo/man' essences of experience. This was the principal theoretical and methodological framework that guided the research into participants' lived experience of the Mentro Allan Programme, and specifically their encounters with the weather. Here, I investigate the participants' 'weather-worlds' (Ingold 2010), exploring the ways in which people experience 'living' the weather in the outdoor environments in which the exercise projects operated. For phenomenology, as noted above, our minds and bodies are inextricably connected to, and interwoven with the fabric of the world, so that mind/body/world are closely braided, and mutually influencing. A phenomenon is not therefore separate from human consciousness and experience, but forms a part of our incarnate subjectivity, as was found to be the case vis-à-vis participants' living the weather, and 'mingling' (Ingold 2007) with the elements.

As Vannini and colleagues (2012, p. 362-363) identify, weather has occupied somewhat of an 'absent-presence' in much social science research, including sociological 
and (some) anthropological research, even though the ways in which people experience and talk about weather are sociologically significant and valuable. As these authors also highlight, the ways in which people develop emotional attachments to weather, how they sense and comprehend meteorological processes and imbue them with significance, is of considerable research interest. The current findings therefore contribute to a small sociological literature on weather (for example, Vannini et al. 2012, Mason 2016) and 'weather-worlds' (Ingold 2010), and cohere strongly with Ingold's (2010, p. S122) insight, that 'the experience of weather lies at the root of our moods and motivations' (italics in original). The Mentro Allan Programme is described in the next section, along with the methods utilised for the ethnographic component ${ }^{\mathrm{ii}}$ of the study.

\section{The research: ethnographic encounters with Mentro Allan}

The research project involved a 2-year ethnographic study of a Welsh national programme, Mentro Allan (meaning: Venture Out), rolled out in 14 different physical activity and exercise projects across Wales, in both urban and rural locations. Mentro Allan aimed to increase physical activity and exercise levels amongst specific 'target groups' considered to be less physically active than the population in general (BLF 2009). It focused on encouraging exercise in the outdoors generally rather than specific involvement in 'sports', and sought particularly to increase physical activity and exercise levels amongst socially and economically disadvantaged groups. As Woodward (2009) notes, and as is commensurate with my combined phenomenological and sociological theoretical lens, material bodies embody inequalities and are both represented and experienced as 'marginalised'. Material and social bodies can thus be marginally situated via a gamut of structural and cultural forces, on the grounds of, for example, age, gender, ethnicity, 'race', forms of dis/ability, and so on. Locating bodies as 'marginalised' and 
'less active' was central to Mentro Allan, which incorporated two principal aims: i) to encourage a diverse range of less active 'target groups' to engage (and sustain engagement) with physical activity and exercise; and ii) to promote physical activity and exercise in the outdoors. The Programme itself used 'doorstep' outdoor locations (those not far from participants' homes) in order to minimise the impact of travel and to maximise accessibility and sustainability of engagement.

The funded research project investigated Mentro Allan, including identifying whether and in what ways it was successful in increasing and sustaining increased physical activity/exercise levels amongst 'target groups' of relatively inactive people in Wales. Ethical approval for the project was granted by the relevant University Ethics Committee, and a mixed-methods approach was adopted, combining survey data with an in-depth qualitative approach. This latter included ethnographic case studies of six specific projects, incorporating participant observation with a range of activity groups over a period of almost two years; 'participation' involved taking part in all the activities offered by the specific project. It is this ethnographic component of the research from which are drawn the findings I discuss below. In addition to participant observation, indepth interviews, primarily semi-structured and unstructured conversational interviews, were undertaken with 68 exercise participants, termed 'beneficiaries'. These individuals were selected via purposive sampling - supplemented with opportunistic sampling for the unstructured conversational interviews that took place during actual activities employing criteria of gender, age, social class (where known), degree of dis/ability, and type of activity, in order to provide as wide a range of perspectives as could be garnered. Criteria of generalisability and representativeness were not, it should be noted, aims of the research. Interviews were also conducted with 44 members of project staff and 34 
other people involved in the Programme, such as volunteer workers and support workers, as follows:

Project staff:

Others involved with projects

(service providers, volunteers and support workers):

Programme participants (termed 'beneficiaries'):

The primary aim of the qualitative research was to allow participants to portray and explore their own lived experiences and identify phenomena significant to them in engaging with exercise in the outdoors. Phenomenological bracketing or epochē was undertaken (see also Allen-Collinson 2011a) throughout the research, in an attempt to identify and challenge, as far as possible, presuppositions regarding outdoor exercise. For example, some projects held prior assumptions about the homogeneity of target groups, and the 'appropriateness' of forms of exercise for particular social groups, such as 'gentle' exercise for older adults, and/or some BME beneficiaries, particularly 'veiled' women observing religious principles. Semi-structured interviews were around an hour's duration, while mobile (during exercise) interviews tended to be of shorter duration. Commensurate with phenomenological interviews (and many forms of qualitative interviews more generally), these interviews were not construed as granting privileged access to some inner private self (Smith and Sparkes 2005) but regarded as coconstructions, interactionally produced in the interview context. A specialist audiotranscriber transcribed the interview recordings. Data analysis generally followed Giorgi's (1997) phenomenological guidelines, involving: i) the assembling of concrete descriptions of phenomena from participants; ii) the adoption of the phenomenological attitude (using bracketing); iii) initial impressionistic transcript reading; iv) in-depth rereading of descriptions to identify initial themes and sub-themes; v) the production of general statements of the structures of phenomena. Whilst participants were not asked 
specifically about their experiences of, and feelings about the weather, these nevertheless emerged strongly, and unprompted, as a key element in people's sensory engagement with the outdoor exercise environment, eliciting accounts of sometimes intense embodiment (Allen-Collinson and Owton 2015) encounters with the weather.

\section{The findings}

From the research findings, the importance of the sensorial elements emerged strongly, in particular participants' engagement with, and intermingling or 'commingling' (Ingold 2007) with the elements of the outdoor environments, including the weather. In people's accounts of their lived experience of exercise in the outdoors, vectors of sensory experience were, for the most part, intertwined, producing a synaesthetic experience (Allen-Collinson 2011a) where the senses intermingled. So, for example, the sight of colourful wildflowers out on a walk might mingle with the olfactory and the haptic, so that once perceived visually, the flowers might also be touched and smelled. Or, detecting the pungent scent of wild garlic in the woods, one might then seek out a visual encounter with the tiny white-star flowers. Weather encounters were similarly recounted as multisensory.

At this juncture, I should highlight some of the challenges involved in verbal and textual representation of sensory (and other lived-body) experiences, as has been noted in the qualitative research literature (see for example, Merchant 2011, Sparkes and Smith 2012, Allen-Collinson and Owton 2014). Difficulties can be encountered in seeking to portray evocatively but also analytically the kinds of corporeal practices and experiences not usually 'translated' into visual form (Allen-Collinson and Owton 2015). With regard to certain forms of intense embodiment experiences, interviewees seemed to struggle at times to convey verbally these instances of heightened, sometimes acute, sensory 
awareness. I am therefore conscious that much can be 'lost in translation', but hope that nevertheless participants' quotes will engender some degree of sensory recognition, even a vicarious sensorial response in the reader, in a kind of sensory-intersubjectivity (AllenCollinson et al. 2016), despite the limitations of the text.

Encounters with a whole range of meteorological conditions were recounted by participants, with many enjoying exercising, and supervising exercise, in 'fair weather', which usually meant sunshine or at least fine, dry conditions:

I like doing indoors, to do writing and stuff about gardening and wildlife, but the outdoor, like doing stuff like doing the weeding and digging and taking branches down and making the path, sorting the plants out and putting seeds in the soil. That's what I like doing outside if it's a nice day (Young beneficiary with mental health issues).

She's alright if it's nice weather. Bad weather, no good ... she'd be alright going in good weather but bad weather would put her off. Other people I've worked with, it doesn't matter whether it's sunny or bad, they'll still go on the bike because they enjoy doing it (carer).

Interestingly, however, the term 'weather' was sometimes taken to mean 'bad weather' or at least problematic weather conditions, requiring some shelter until the 'weather stopped' (as one carer described). This was highlighted as a concern, particularly (but not exclusively) for those individuals deemed more 'vulnerable' within the Mentro Allan Programme: 
The only thing I would say, if they had somewhere for the people to sit. They have somewhere outside to sit and drink, where they've got the port cabins [Portakabins - portable small buildings] but I think with people like in wheelchairs, you might need something inside because of the weather, and if you had something inside, at least they could stay there for an hour or two until the weather stopped, and then go out again later on (carer)

For some participants, it was the pleasures of being in the outdoors, whatever the weather, that were valorised and celebrated, even when the weather itself was deemed 'really rubbish or 'really awful'. Here, a young woman expresses the sheer exhilaration and intense embodiment of being out in the elements, particularly the howling wind of the hill tops:

... do you know what, I really like it when the weather's really rubbish as well; sometimes it's just crazy, in the winter going up where it's really snowy or when the weather's really awful and the wind's howling across and you're just basically having to hold on to rocks and not get blown off the top of the hill, it's brilliant, you just laugh and it's great. I just love it up there (young female participant).

Similarly, a young man described his love of the rain and how, for him, wet weather conditions would not deter him from going to exercise outdoors. Certainly, the much maligned, Welsh/British rain was not perceived as a reason for inhibiting his daily walk: 
Love it, I love the rain. I'm not afraid of the rain. If I'm going for a walk, I go for a daily walk, and if it's raining I'll still go, it won't prevent me from leaving my house or anything like that. It's just rain. Most people don't want to get wet, and they've got an umbrella and they stay in and stuff like that, or get a blanket and put a DVD on - it's just another day to me, it's just raining. The weather doesn't put me off at all (young male participant).

Even for those who did not express an active love of rain, any portrayed somatic 'problems' generated by encountering cold and/or heavy rain were noted as transient and manageable, so long as people could engage in 'temperature work' (Hockey and AllenCollinson 2017) to restore bodily warmth and comfort:

No. I don't mind, so long as, I don't mind if it's freezing cold or pouring with rain, so long as you've got hot water and dry clothes at the end of your journey, then you'll never catch a cold, because the first thing you've got to do is strip off your wet clothes and jump in a hot bath and have a soak and you're fine. I've never had a cold through walking in the rain (older person).

Analogously to some of the residents of the famously wet coastal region of British Columbia in Canada, studied by Vannini and colleagues (2012, p.365), the above young man had 'learn[ed] to love what many people in the world have come to despise': that is, the rain. Although it was not possible to ascertain from the above quote whether this particular participant had always enjoyed the rain, it emerged clearly from others' accounts that they had learned to engage with, tolerate, endure and even enjoy meteorological conditions that are more often construed by others as unpleasant, if not 
actually 'despised'. It is to this form of somatic, weather learning, as a component of what I term 'weather work', that I now turn.

\section{Weather work and learning to weather}

The British weather is notoriously mercurial, and sudden shifts from bright, warm(ish) sunshine to icy wind and rain are not at all unusual, particularly in upland areas, requiring of inhabitants a certain kind of 'weather endurance' (see Hockey and Allen-Collinson 2015) or 'weathering' attitude (Vannini et al. 2012). Vannini and colleagues (2012, p. 362) note that, 'To weather is an active, reflexive, practical disposition to endure, sense, struggle, manipulate, mature, change, and grow in processes that, over time, implicate the place-making of one's dwelling'. For me, this sense of active, reflexive, at times mindful, engagement with, and sense-making vis-à-vis weather, is integral to what I term, 'weather work'. This conceptualisation draws on the theoretical traditions of phenomenological sociology, its off-shoot ethnomethodology, and symbolic interactionism, specifically to refer to the lived experience of weather as not only 'received' and felt by human actors, but also as actively constructed, (re)interpreted, made sense of, (re)produced and communicated via social interaction, contoured by historical, social-structural and sociocultural frameworks. This perspective coheres with notions of the active 'production' of the sensory (see for example, Chau 2008, Allen-Collinson and Owton 2015), in that social actors must undertake work in sensory-production as well as in sensory-interpretation. The findings revealed evidence of Mentro Allan participants having to engage (sometimes unwillingly initially) in such weather work, and in somatic, sensory, 'weather learning', in order to become comfortable with, and appreciate a range of less obviously pleasant weather elements. Those somatically unfamiliar with outdoor exercise sometimes struggled initially to cope with the elements, particularly with the rain, which could 
generate negative corporeal experiences. A support worker noted how she had to engage in weather work with her clients, some of whom initially refused to go out at all in rainy conditions, even in a light drizzle:

Just perseverance, because when he first came to us last year, he wouldn't go out in the rain, even a drop, even a drizzle, we'd have major crises with him, but now, that's what I'm saying about, for him, he's experienced all this that he wouldn't normally experience. We're not making them do it, but because we're there and it rains, well it's raining, we're going to get wet... if you want to stay on the bikes you can get wet, if you want to stay dry you'll have to get off the bike, so it's his choice to stay on (female support worker).

As part of people's involvement in the Mentro Allan Programme, they were inevitably exposed to a range of weather conditions in the outdoors and the above support worker highlights the importance of experiential learning and weather work in familiarising Programme participants with the elements, including conditions initially defined as problematic for outdoors exercise. A quote from a project coordinator further underlines the experiential weather-learning involved, and the importance of undertaking weather work, in terms of making determined efforts to engage with weather conditions that are not immediately construed as positive:

On rainy days participants have often said that, well, when they woke up and saw the weather they almost didn't want, didn't come along, but having come the rain didn't spoil the experience and they were glad to have made the effort. My suggestion is that the perception of the impact of the weather is different 
from the reality of the experience... anyone who has had the opportunity to experience outdoor activity in the rain (perhaps because the weather's good at the start of the day but changed for the worse during the activity) is less likely to be put off by the weather in the future as they often have a positive experience they can draw on (project coordinator).

Drawing on such weather memories, as in the above instance, can constitute a key part of weather work, as individuals learn through experience that they are able to endure certain weather conditions, and are subsequently less likely to be deterred from exercising in the outdoors due to rain or other less clement weather conditions.

In some cases, such weather learning and weather work were more planned, directed, and even formalised. So, for example, project coordinators and other project staff and support workers described their deliberate efforts to expose participants to a gamut of weather conditions in order to enhance sensory and weather learning. In the following instance, encountering the rain and/or cold was rendered part of participants' sensory, weather education, especially for those with learning disabilities:

We've [project staff] decided that we'd just go regardless of the weather. We'd maybe shorten the visit but we'll still go, because again you need that sensory input, as long as they're warm enough, they won't be getting hypothermia, and they need to experience cold, they need to experience wet, because that's part of their sensory development... The only thing we wouldn't do is if it's snowing but we go out all weathers, it doesn't matter what the weather (female support worker of young people with learning disabilities) 
Similarly, whilst health concerns were highlighted with regard to exposure to very cold or wet conditions, particularly for those groups deemed 'vulnerable' within the Programme, participants also reported that, equipped with appropriate clothing and kit, the weather could be 'managed', including by limiting exposure to its more deleterious effects:

Just the fact that because obviously any infection or stuff like that could be potentially serious, health implications to him ... It's not just getting a cold, it will develop into pneumonia and then it's quite serious ... he could go and do a bit of outdoor cycling, just like you wouldn't be out for an hour, it would be 20 minutes, half an hour, and we can take blankets and stuff like that and he's got one of these 'snuggies', he's got one of these things that you put down that comes up over his feet, so we could put that on the little bicycle thing, wrap him up warm. Yes, we'd still go out for fresh air and stuff like that, so long as it's not bitter cold out there, and dependent on weather in the winter (carer).

These then were the salient themes that emerged from the ethnographic component of the research, coalescing around the lived experience of weather in the outdoor projects that were organised under the aegis of the Mentro Allan Programme. As highlighted in the findings, engagement in weather learning and weather work were revealed as core elements in participants' experiences, and were identified by social actors at all levels of the Programme, from beneficiaries and their carers and/or support workers, to project coordinators. 


\section{Conclusion}

Drawing on insights derived from a sociologised form of phenomenology, in this article I have explored some of the somatic, sensory, 'lived weather' experiences of participants in a national physical activity and exercise programme, Mentro Allan, which utilised the outdoor environments of Wales to engage relatively 'inactive' target groups in physical activity and exercise. Calls have recently been made (e.g. Mason and Davies 2009; Pink 2009; Sparkes 2009) for new qualitative research into the complexities of lived sensory experience. This article responds to that call by contributing original insights to a small, but developing phenomenological sociological literature on the senses. More specifically, it seeks to remedy directly the notable 'absent-presence' of weather (Vannini et al. 2012) as an explicit theoretical and substantive focus in social science research, despite its importance in social interaction and in social life generally, and consequently its sociological significance. The article thus contributes theoretically to an emergent sociological literature on weather (Vannini et al. 2012; Mason 2016) and the exploration of 'weather-worlds' (Ingold 2010). Drawing on key themes that emerged from 146 participants' accounts, I have delineated above my original conceptualisation of weather learning and weather work and their salience in participants' experiences of outdoor exercise.

These concepts are based in and derived from the theoretical traditions of phenomenological sociology (including its foundationally challenging off-shoot, ethnomethodology), and symbolic interactionism. Here, I highlight that the lived experience of weather often involves its active 'production' and reproduction by agentic social actors who interpret and re-interpret, make sense of, and communicate 'lived weather' in social interaction, as contoured by historical, social-structural and sociocultural frameworks. To give an instance of the impact of a key sociological variable, 
socio-economic class (or at least income level), some of the Mentro Allan projects provided their beneficiaries with cold- and/or wet-weather gear free of charge or at considerably reduced prices. Having access to specialist clothing, which they would not otherwise have been able to afford, subsequently permitted those on low incomes to participate in outdoors exercise even in heavy rain or cold conditions. Such participation and familiarisation facilitated weather work and resulted in a perceptual shift, so that heavy rain and/or low temperatures were no longer perceived to be the strong rationale for 'not going out', which participants recounted having felt prior to their weatherlearning experiences.

Furthermore, in the spirit of phenomenology, I have sought to portray and give voice to the 'lived weather' experiences of research participants without resort to undue abstraction and 'grand' theorisation. Whilst the challenges of encoding in textual form our sensory (and other) instances of intense embodiment have been acknowledged, nevertheless I hope that something of the raw, vital, shifting, elemental, lived experience of the weather, and the sensuous delights and difficulties of engaging in weather learning and weather work still somehow emerge from the written text. Whilst the macrostructural features of the Mentro Allan Programme are without doubt important, in being able to ascertain general trends in participation (and drop-out), for example according to gender, age, socio-economic class, degree of dis/ability, ethnicity, and so on, nevertheless, the individual, existential, and material-bodied dimension must not be neglected. The nexus of sociology and phenomenology provides a powerful analytic perspective in situating people's own lived-body experiences within wider social structures and socio-cultural frameworks, and discerning patterns or structures of experience. Such experiences can have a fundamental and durable impact upon people's 
ways of being-in-the-world, including whether or not they are persuaded to engage (and sustain engagement) with exercise and/or physical activity.

Whilst the purpose of the current article was not evaluative of the Mentro Allan Programme in terms of the latter's success (or not) in promoting and sustaining exercise behaviour change, nevertheless, the importance of somatic engagement with the outdoors generally, and with the weather and weather work in particular, may well have implications for outdoor exercise and physical activity schemes similar to Mentro Allan. For, if weather learning can be developed and enhanced in a graduated fashion, those initially unfamiliar with, even threatened by, feelings of body-mind exposure to the gamut of weather conditions, can be supported in their weather work, to the point where they may feel more confident in, embrace and even enjoy (as did many participants) the most mercurial vagaries of the weather. This in turn may well help motivate and sustain motivation to engage in exercise and physical activity in the ever-shifting weatherelements of outdoor environments (see also Allen-Collinson et al. 2011, Allen-Collinson and Leledaki 2015).

Word count: 7679 


\section{References}

Allen-Collinson, J., 2009. Sporting embodiment: sports studies and the (continuing) promise of phenomenology. Qualitative Research in Sport and Exercise, 1 (3), 279296.

Allen-Collinson, J., 2011a. Intention and epochē in tension: autophenomenography, bracketing and a novel approach to researching sporting embodiment. Qualitative Research in Sport, Exercise and Health, 3 (1), 48-62.

Allen-Collinson, J., 2011b. Feminist phenomenology and the woman in the running body. Sport, Ethics \& Philosophy, 5 (3), 287-302.

Allen-Collinson, J. and Hockey, J., 2011. Feeling the way: notes toward a haptic phenomenology of scuba diving and distance running. International Review for the Sociology of Sport, 46 (3), 330-345.

Allen-Collinson, J., Curry, N., Leledaki, A., Clark, M., 2011. Mentro Allan/Venture Out Evaluation: Lived Experiences of Physical Activity in Outdoor Environments. Final Report to Sport Wales. Cardiff: Sport Wales/Chwaraeon Cymru. DOI: 10.13140/RG.2.1.4160.3689.

Allen-Collinson, J. and Owton, H., 2014. Take a deep breath: asthma, sporting embodiment, the senses, and 'auditory work'. International Review for the Sociology of Sport, 49 (5), 592-608.

Allen-Collinson, J. and Leledaki, A., 2015. Sensing the outdoors: a visual and haptic phenomenology of outdoor exercise embodiment. Leisure Studies, 34 (4), 457-470

Allen-Collinson, J. and Owton, H., 2015. Intense embodiment: senses of heat in women's running and boxing. Body \& Society, 21 (2), 245-268. Video abstract: http://theoryculturesociety.org/video-allen-collinson-owton-on-intense-embodiment/ 
Allen-Collinson, J., Vaittinen, A., Jennings, G. and Owton, H., 2016. Exploring lived heat, 'temperature work' and embodiment: novel auto/ethnographic insights from physical cultures. Journal of Contemporary Ethnography. Online early: http://journals.sagepub.com/doi/pdf/10.1177/0891241616680721

Barton, J., Hine, R. and Pretty J., 2009. The health benefits of walking in greenspaces of high natural and heritage value. Journal of Integrative Environmental Sciences, 6 (4), $1-18$.

Big Lottery Fund (BLF), 2009. Summary of the Community Sport Initiative: Year three evaluation report. London: BLF. Available from: $\underline{\text { www.biglotteryfund.org.uk }}$

Bowler, D., Buyung-ali, L., Knight, T. and Pullin, A., 2010. A systematic review of evidence for the added benefits to health of exposure to natural environments. $B M C$ Public Health, 10, 456.

Caspersen, C.J., Powell K.E. and Christensen G., 1985. Physical activity, exercise and physical fitness: definitions and distinctions of health-related research. Public Health Reports 100, 126-131.

Chau, A.Y., 2008. The sensorial production of the social. Ethnos, 73 (4), 485-504.

Clegg, J. L. and Butryn, T., 2012. An existential phenomenological examination of parkour and freerunning. Qualitative Research into Sport, Exercise and Health, 4 (3), $320-340$.

Crone D., Johnston LH., Gidlow C., Henley, C. and James D.V.B., 2008. Uptake and participation in physical activity referral schemes in the UK: an investigation of patients referred with mental health problems. Issues in Mental Health Nursing 29, 1088-1097. 
Crust, L., Keegan, R., Piggott, D. and Swann, C., 2011. Walking the walk: a phenomenological study of long distance walking. Journal of Applied Sport Psychology, 23 (3), 243-262.

Crust, L., Swann, C., Allen-Collinson, J., Breckon, J. and Weinberg, R., 2014. A phenomenological exploration of exercise mental toughness: perceptions of exercise leaders and regular exercisers. Qualitative Research in Sport, Exercise and Health, 6 (4): 441-461.

Crust, L., Swann, C., Allen-Collinson, J., 2016. The thin line: a phenomenological study of mental toughness and decision-making in elite, high-altitude mountaineers. Journal of Sport \& Exercise Psychology, 38 (6), 598-611.

Curry, N.R., 2009. Leisure in the landscape: rural incomes and public benefits. In A. Bonn, K. Hubacek,, T.E. Allott and J. Stuart, eds. Drivers of environmental change in uplands. London: Routledge.

Curry, N. and Brown, K., 2010. Differentiating outdoor recreation: evidence drawn from national surveys in Scotland. Journal of Policy Research in Tourism, Leisure and Events, 2 (1), 29-50.

Darker, C.D., Larkin, M. and French, D.P., 2007. An exploration of walking behaviour - an interpretative phenomenological approach. Social Science \& Medicine, 65, 217283.

Department of Health, 2011. UK Physical Activity Guidelines. Available at: https://www.gov.uk/government/publications/uk-physical-activity-guidelines; cited 1 February, 2017.

Gidlow, C., Johnston, L.H., Crone, D., and James, D.V.B. 2005. Attendance of exercise referral schemes in the UK: A systematic review. Health Education Journal, 64 (2), $168-186$. 
Giorgi, A., 1997. The theory, practice, and evaluation of the phenomenological method as a qualitative research procedure. Journal of Phenomenological Psychology, 28, $235-261$.

Hale, J., Knapp, C., Bardwell, L., Buchenau, M., Marshall, J., Sancar, F. and Litt, J.S., 2011. Connecting food environments and health through the relational nature of aesthetics: gaining insight through the community gardening experience. Social Science \& Medicine, 72, 1853-63

Hardman, A.E., Stensel, D.J., 2003. Physical activity and health the evidence explained. London: Routledge.

Henderson, H., Evans, A.B., Allen-Collinson, J., Siriwardena, A.N., 2017 in press. 'Wild and woolly' world of Exercise Referral Schemes: contested interpretations of an exercise as medicine programme. Qualitative Research in Sport, Exercise and Health, DOI: $10.1080 / 2159676 X .2017$.

Hockey, J., 2011. Knowing the 'going': the sensory evaluation of distance running. Qualitative Research in Sport, Exercise and Health, 5 (1), 127-141.

Hockey, J. and Allen-Collinson, J., 2007. Grasping the phenomenology of sporting bodies. International Review for the Sociology of Sport, 42 (2), 115-131.

Hockey, J. and Allen-Collinson, J., 2015. Digging in: the sociological phenomenology of 'doing endurance' in distance-running. In W. Bridel, P. Markula and J. Denison, eds, Endurance running: A socio-cultural examination. London: Routledge, 227-242.

Hockey, J. and Allen-Collinson, J., 2017. Running a temperature: sociologicalphenomenological perspectives on distance running, thermoception and 'temperature work'. In A.C. Sparkes, ed. Seeking the senses in physical cultures: sensual scholarship in action. London: Routledge, 42-62. 
Hogeveen, B., 2011. Skilled coping and sport: promises of phenomenology. Sport, Ethics and Philosophy, 5 (3), 245-255.

Hughson, J. and Inglis, D., 2002. Inside the beautiful game: towards a Merleau-Pontian phenomenology of soccer play. Journal of the Philosophy of Sport, XXIX, 1-15.

Humberstone, B., 2011. Embodiment and social and environmental action in naturebased sport: spiritual spaces. Leisure Studies, 30, 495-512.

Husserl, E., 1970. The crisis of European sciences and transcendental phenomenology (trans. D. Carr). Evanston, IL: Northwestern University Press.

Ingold, T., 2007. Earth, sky, wind, and weather. Journal of the Royal Anthropological Institute (N.S.), S19-S38.

Ingold, T. 2010. Footprints through the weather-world: walking, breathing, knowing. Journal of the Royal Anthropological Institute (N.S.), S121-S139.

Jarrett, H., Peters, D. and Robinson, P., 2004. Evaluating the 2003 Step-o-meter loan pack trial. Report to the British Heart Foundation and the Countryside Agency.

Kerry, D.S. and Armour, K.M., 2000. Sports sciences and the promise of phenomenology: philosophy, method, and insight. Quest, 52 (1), 1-17.

Maas, J., Verheij, R.A., Groenewegen, P.P., de Vries, S. and Spreeuwenberg, P., 2006. Green space, urbanity, and health: how strong is the relation? Journal of Epidemiology and Community Health, 60, 587-592

Martínková, I. and Parry, J., 2011. An introduction to the phenomenological study of sport. Sport, Ethics and Philosophy, 5 (3), 185-201.

Mason, J. and Davies, K., 2009. Coming to our senses? A critical approach to sensory methodology. Qualitative Research, 9 (5), 587-603.

Mason, J., ed. 2016. Living the weather: voices from the Calder Valley. Manchester: Morgan Centre for Everyday Lives. 
Merchant, S., 2011. The body and the senses: visual methods, videography and the submarine sensorium. Body and Society, 17, 53-72.

Merleau-Ponty, M., 2001. Phenomenology of perception (trans. C. Smith). London: Routledge \& Kegan Paul.

Natural England, 2007. Walking the way to health initiative. Accessed 15 August, 2015. Available at:

http://www.countryside.gov.uk/LAR/Recreation/WHI/index.asp

NHS Health Scotland, 2007. The Health Implications of Sedentary Behaviour, Physical Activity Briefing Paper 13. Edinburgh: NHS Scotland. Accessed 25 August, 2016. Available at:

http://www.healthscotland.com/uploads/documents/5724-13\%20The\%20Health\%20Implications\%20of\%20Sedentary\%20Behaviour.pdf

Nettleton, S., 2013. Cementing relations within a sporting field: fell running in the English Lake District and the acquisition of existential capital. Cultural Sociology, 7 (2), 196-210.

Pate, R.R., O'Neill, J.R., Lobelo, F., 2008. The evolving definition of 'sedentary': the definition and measurement of sedentary behaviour. Exercise \& Sport Science Reviews, 36 (4), 173-178

Pink, S., 2009. Doing sensory ethnography. London: Sage.

Ravn, S., and Hansen, H.P., 2013. How to explore dancers' sense experiences? a study of how multi-sited fieldwork and phenomenology can be combined. Qualitative Research in Sport, Exercise and Health, 5 (2), 196-213.

Ronkainen, N.J., Harrison, M.E. and Ryba, T.V., 2014. Running, being, and Beijing - an existential exploration of a runner identity. Qualitative Research in Psychology, 11(2), 189-210. 
Smith, B. and Sparkes, A.C., 2005. Analyzing talk in qualitative inquiry: exploring possibilities, problems and tensions. Quest, 57, 213-242.

Sokolowski, R., 2000. Introduction to phenomenology. Cambridge: Cambridge University Press.

Sparkes, A., 2009. Ethnography and the senses: challenges and possibilities. Qualitative Research in Sport and Exercise, 1(1), 21-35.

Sparkes, A. and Smith, B., 2012. Embodied research methodologies and the senses in sport and physical culture: a fleshing out of problems and possibilities. In K. Young and M. Atkinson, eds. Qualitative research in sport and physical culture. Castle Hill, Au: Emerald Press, 169-192.

Spencer, D.C., 2014. Sensing violence: an ethnography of mixed martial arts. Ethnography, 15 (2), 232-254.

Swann, C., Crust, L. and Allen-Collinson, J. 2016. Surviving the 2015 Mount Everest disaster: a phenomenological exploration into lived experience and the role of mental toughness. Psychology of Sport \& Exercise, 27, 157-167.

Throsby, K., 2013. 'If I go in like a cranky sea lion, I come out like a smiling dolphin': marathon swimming and the unexpected pleasures of being a body in water. Feminist Review, 103, 5-22.

Vannini, P., Waskul, D., Gottschalk, S. and Ellis-Newstead, T., 2012. Making sense of the weather: dwelling and weathering on Canada's Rain Coast. Space and Culture, 15 (4), 361-380.

Wacquant, L., 2004. Body and soul: notebooks of an apprentice boxer. Oxford: Oxford University Press.

Woodward, K., 2009. Bodies on the margins: regulating bodies, regulatory bodies. Leisure Studies, 28 (2), 143-156. 
World Health Organisation (WHO), 2003. World Health Report 2003. Geneva: WHO.

World Health Organisation (WHO), 2010. Global recommendations on physical activity for health. Available at:

http://www.who.int/dietphysicalactivity/publications/9789241599979/en/; cited 5 June, 2017.

\section{Acknowledgements}

My thanks to members of the full research team: Professor Nigel Curry (University of the West of England), Dr Aspasia Leledaki (University of Exeter), and Dr Michael Clark (University of Gloucestershire), for all their help in undertaking the research, and for permission to use data in this particular publication.

The research upon which this article is based was commissioned and funded by Sport Wales to evaluate the Mentro Allan Programme. Mentro Allan was a Big Lottery-funded initiative managed by a National Partnership of organisations, including: Sport Wales, Countryside Council for Wales, Public Health Wales, Wales Council for Voluntary Action, and the Welsh Local Government Association.

\footnotetext{
i The Big Lottery Fund is a non-departmental public body responsible for distributing funds raised by the National Lottery for 'good causes'. Since 2004 it has awarded over $£ 6.2$ billion to more than 130,000 projects across the UK. See: https://www.biglotteryfund.org.uk/

ii The overall research project utilised a mixed-methods approach, but here it is the ethnographic component upon which I focus here.
} 